\title{
Tumoral and Choroidal Vascularization
}

\author{
Differential Cellular Mechanisms Involving Plasminogen \\ Activator Inhibitor Type I
}

\author{
Maud Jost, ${ }^{*}$ Catherine Maillard, ${ }^{*}$ Julie Lecomte, ${ }^{*}$ \\ Vincent Lambert, ${ }^{*}$ Marc Tjwa, ${ }^{\dagger}$ Pierre Blaise, ${ }^{\neq}$ \\ Maria-Luz Alvarez Gonzalez, ${ }^{,}$Khalid Bajou, ${ }^{*}$ \\ Silvia Blacher, ${ }^{*}$ Patrick Motte, ${ }^{\S}$ Chantal Humblet, ${ }^{\pi}$ \\ Marie Paule Defresne, "I Marc Thiry," \\ Francis Frankenne, ${ }^{*}$ André Gothot, ${ }^{* *}$ \\ Peter Carmeliet, ${ }^{\dagger}$ Jean-Marie Rakic, $^{\neq}$ \\ Jean-Michel Foidart, ${ }^{* \dagger \dagger}$ and Agnès Noël ${ }^{*}$ \\ From the Laboratories of Tumor and Development Biology* and \\ Histology, "Centre de Recherche en Cancérologie Expérimentale \\ (CRCE), Groupe Interdisciplinaire de Génoprotéomique Appliquée \\ (GIGA-R), Center for Biomedical Integrative Genoproteomics, the \\ Department of Life Sciences, ${ }^{\varsigma}$ Laboratory of Plant Cell Biology, \\ the Laboratories of Cell and Tissue Biology" and Hematology,** \\ and the Departments of Ophthalmology ${ }^{\ddagger}$ and Gynecology, ${ }^{+t}$ \\ Centre Hospitalier Universitaire, University of Liège, Liège; and \\ the Center for Transgene Technology and Gene Therapy, ${ }^{\dagger}$ \\ Katholieke Universiteit Leuven, Leuven, Belgium
}

An adequate balance between serine proteases and their plasminogen activator inhibitor-1 (PAI-1) is critical for pathological angiogenesis. PAI-1 deficiency in mice is associated with impaired choroidal neovascularization (CNV) and tumoral angiogenesis. In the present work, we demonstrate unexpected differences in the contribution of bone marrow (BM)-derived cells in these two processes regulated by PAI-1. PAI-1 ${ }^{-1-}$ mice grafted with BM-derived from wild-type mice were able to support laser-induced $\mathrm{CNV}$ formation but not skin carcinoma vascularization. Engraftment of irradiated wildtype mice with $\mathrm{PAI}-1^{-/-} \mathrm{BM}$ prevented $\mathrm{CNV}$ formation, demonstrating the crucial role of PAI-1 delivered by BM-derived cells. In contrast, the transient infiltration of tumor transplants by local PAI-1-producing host cells rather than by $B M$ cells was sufficient to rescue tumor growth and angiogenesis in PAI-1-deficient mice. These data identify PAI-1 as a molecular determinant of a local permissive soil for tumor angiogenesis. Altogether, the present study demonstrates that different cellular mechanisms contribute to PAI-1-regulated tumoral and CNV. PAI-1 contributes to BM-dependent choroidal vas- cularization and to BM-independent tumor growth and angiogenesis. (Am J Pathol 2007, 171:1369-1380; DOI: 10.2353/ajpath.2007.070074)

Plasminogen activator inhibitor type 1 (PAl-1) is a key regulator of the plasminogen activator (PA)-plasmin system, a proteolytic cascade implicated in various physiological and pathological processes including vascular thrombolysis, inflammation, wound healing, choroidal neovascularization (CNV) associated with age-related macular degeneration and cancer progression. PAl-1 is the main physiological inhibitor of urokinase-type plasminogen activator (UPA) and tissue-type plasminogen activator (tPA), two serine proteases that both convert the inactive zymogen plasminogen into active plasmin. ${ }^{1,2}$ By its capacity to degrade a variety of matrix components and to activate matrix metalloproteinases (MMPs) as well as growth factors, plasmin is a key regulator of various physiological and pathological processes associated with pericellular remodeling. In clinical studies, elevated PAI-1 levels have been correlated with various chorioretinal pathologies ${ }^{3,4}$ and are predictive of poor survival for patients suffering from different types of cancer., ${ }^{5,6}$ By applying different experimental models into PAI-1-deficient mice (PAl-1 ${ }^{-1-}$ mice), a crucial role has been dem-

Supported by the Communauté Française de Belgique (Actions de Recherches Concertées), the Commission of European Communities (FP6), the Fonds de la Recherche Scientifique Médicale, the Fonds National de la Recherche Scientifique (Belgium; to M.J., C.M., J.L., and K.B.), the Fédération Belge Contre le Cancer, the Fonds Spéciaux de la Recherche (University of Liège), Les Amis des Aveugles (Ghlin, Belgium), the Centre Anticancéreux près I'Université de Liège, the FB Assurances, the Fondation Léon Frédérica (University of Liège), the Direction Générale des Technologies, de la Recherche et de l'Energie from the "Région Wallonne," and the Interuniversity Attraction Poles Programe-Belgian Science Policy (Brussels, Belgium).

Accepted for publication June 25, 2007

Address reprint requests to Agnès Noel, Laboratory of Tumor and Developmental Biology, University of Liège, Tour de Pathologie, CHU (B23), Sart Tilman; B-4000 Liège, Belgium. E-mail: agnes.noel@ulg.ac.be. 
onstrated for PAl-1 in tumor growth and angiogenesis, ${ }^{7-9}$ as well as in CNV, ${ }^{10}$ which is the hallmark of the most severe form of age-related macular degeneration and the major cause of blindness in people 50 years of age or more. The formation of tumor and/or choroidal neovessels may involve different mechanisms including at least angiogenesis, endothelial cell sprouting from pre-existing vessels, and vasculogenesis, recruitment of circulating endothelial progenitor cells into blood vessels. ${ }^{11-14}$

The contribution of BM-derived cells in PAl-1-regulated pathological neovascularization (laser-induced CNV and skin tumor cell transplantation) remains to be determined. PAl-1 can be produced by different cell types such as inflammatory cells (macrophages, mast cells), smooth muscle cells, endothelial cells, and (myo)fibroblasts. The biological relevance of host cells producing PAI-1 during cancer growth and invasion has been demonstrated in the model of malignant keratinocyte transplantation. ${ }^{7,8,15}$ In this system, although the malignant PDVA cells used are able to produce PAI-1, the deficiency of PAI- 1 in mice prevented tumor vascularization and invasion. ${ }^{7}$ Interestingly, although the overexpression of PAI- 1 by tumor cells cannot compensate for host PAI-1 deficiency, ${ }^{16}$ induction of PAl-1 expression in host tissue by using adenoviral vector restored tumor growth and vascularization. ${ }^{7}$

In the present study, we aimed at elucidating and comparing the putative role of BM-derived cells during tumor and CNV formation. Two experimental models (malignant keratinocytes transplantation and laser-induced CNV) were applied to WT $\left(P A l-1^{+/+}\right)$and $P A l-1^{-1-}$ mice previously irradiated and grafted with WT BM cells. We provide evidence that transplantation of wild-type (WT) $\mathrm{BM}$ cells into irradiated PAl-1-1- mice was sufficient to rescue CNV but failed to restore tumor angiogenesis. In contrast to what occurs in CNV formation, in the tumor transplantation system, resident host cells rather than BM-derived cells significantly contribute to the angiogenic process. These data demonstrate for the first time that PAl-1 controls BM-dependent vascularization in ocular disease and BM-independent angiogenesis in skin tumors.

\section{Materials and Methods}

\section{Transgenic Mice}

Homozygous PAl-1-deficient mice $\left(P A l-1^{-1-}\right)$ and their corresponding WT mice with a mixed genetic background of $87 \% \mathrm{C} 57 \mathrm{BL} / 6$ and $13 \% 129 \mathrm{SV} / \mathrm{SL}$ strain were used. $^{7,8,10}$ The corresponding immunodeficient mice were generated in a Rag-1-1- background (PAl-1-1Rag- $1^{-1-}$ and WT Rag-1 ${ }^{-1-}$ mice). ${ }^{17}$ Transgenic mice heterozygous for the enhanced green fluorescent protein (eGFP) under the control of $\beta$-actin promoter C57BL/6$\mathrm{Tg}$ (ACTbEGFP)10sb were obtained from the Jackson Laboratories (Bar Harbor, ME). Mouse experimentation was done in accordance to the guidelines of the University of Liège regarding the care and use of laboratory animals.

\section{Bone Marrow (BM) Transplantation}

BM cells were isolated from the tibia and femur of donor mice, 8 to 10 weeks of age, by slowly flushing RPMI 1640 culture medium (Gibco BRL, Paisley, UK) inside the diaphyseal channel. Recipient mice (8 to 10 weeks old) sublethally irradiated with a single dose of 4 Gy were injected intravenously with $\mathrm{BM}$ cells $\left(10^{7}\right.$ per animal). At 5 weeks after BM transplantation, malignant keratinocytes were transplanted or impact laser burns were performed.

\section{Keratinocyte Transplantation Model}

Malignant murine keratinocytes (PDVA cells) were generated from B10LP mice after a carcinogen treatment (dimethylarsinic acid). Tumor cells $\left(2 \times 10^{5}\right)$ cultured on a collagen gel inserted in Teflon rings (Renner $\mathrm{GmbH}$, Dannstadt, Germany) were covered with a silicone transplantation chamber (Renner $\mathrm{GmbH}$ ) and implanted in toto onto the dorsal muscle fascia of $\mathrm{PAl}_{-1^{-1-}}$ and $\mathrm{PAl}-1^{+/+}$ mice as previously described. ${ }^{7,16,17}$ Three weeks later, transplants were resected, embedded in Tissue Tek (Miles Laboratories, Inc., Naperville, IL), and frozen in liquid nitrogen for cryostat sectioning. ${ }^{8,17}$ In some assays, transplantation chambers were implanted for 1

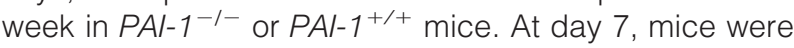
sacrificed, and the whole chambers were harvested with caution, rinsed in PBS, and transferred into new immu-

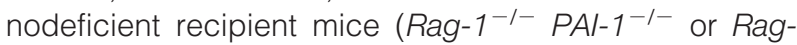
$1^{-/-}$PAl- $\left.1^{+/+}\right) .{ }^{17}$ The chambers were left for 3 additional weeks before harvesting for histological analysis.

\section{Scoring of Tumor Vascularization}

Tumor vascularization was scored as follows: 0 , vessels undetected in the collagen gel; + , vessels infiltrating the collagen gel; and ++ , blood vessels intermingled with invasive epithelial tumor sprouts. Tumors scored + or ++ were considered as angiogenic tumors.

\section{CNV Model}

CNV was induced in both eyes of mice by laser burns as previously described. ${ }^{10}$ After 14 days (or earlier time points in kinetic analysis), animals were sacrificed, and both eyes were enucleated ( $n=4$ to 8 animals per experimental condition with four lesions per eye, ie, eight lesions per animal). For immunohistochemical analysis, eyes were embedded in Tissue Tek for cryostat sectioning. Neovascularization was estimated by computer-assisted measurement on at least five sections per lesion of the $B-C / C$ ratio $(B$, thickness from the bottom of the pigmented choroidal layer to the top of the neovascular membrane; $\mathrm{C}$, thickness of the intact pigmented choroid adjacent to the lesion).

For confocal visualization of the vasculature, mice were injected intravenously with $200 \mu$ l of tetramethylrhodamine isothiocyanate (TRITC)-conjugated dextran (160 kd average molecular weight; Sigma, St. Louis, MO) or fluorescein isothiocyanate (FITC)-conjugated dextran 
$\left(2 \times 10^{3} \mathrm{kd}\right.$ average molecular weight, Sigma) $(50 \mathrm{mg} /$ $\mathrm{ml})$. After 1 hour of fixation in paraformaldehyde $1 \%(\mathrm{pH}$ 7.4), retinas were removed, and choroids were flatmounted using Vectashield mounting medium (Vector Laboratories, Burlingame, CA). Spatial distribution of fluorescence was examined using a Leica TCS SP2 inverted confocal laser microscope (Leica Microsystems, Wetzlar, Germany) equipped with an argon and two helium-neon lasers and an acousto-optical tunable filter for excitation intensity. Digitized images were acquired using a 10× (NA 0.4) or $63 \times$ (NA 1.5) Plan-Apo waterimmersion objective at $1024 \times 1024$-pixel resolution. For multicolor imaging, GFP was visualized by using an excitation wavelength of $488 \mathrm{~nm}$, and the emission light was dispersed and recorded at 500 to $535 \mathrm{~nm}$. TRITC was detected by using an excitation wavelength of 543 and the 488/543-nm dichroic mirror, and the fluorescence emission was dispersed and recorded at 590 to $700 \mathrm{~nm}$. For each lesion, serial optical sections were recorded with a $z$-step of $1.67 \mu \mathrm{m}$. After successive scanning for each interval, the three-dimensional fluorescent images were constructed by using Leica confocal software. The volume of CNV on choroidal flatmount was determined as previously described. ${ }^{18}$

\section{Immunohistochemistry}

Cryostat sections ( $6 \mu \mathrm{m}$ in thickness) were fixed in acetone at $-20^{\circ} \mathrm{C}$ and in methanol $80 \%$ at $4^{\circ} \mathrm{C}$ before incubation with primary antibodies (Abs). For double-immunofluorescent-labeling studies, sections were incubated with two primary Abs. Antibodies raised against type IV collagen (rabbit polyclonal Ab, diluted 1/100; produced in our laboratory), keratin (guinea pig polyclonal $\mathrm{Ab}$, diluted 1/20; Sigma), neutrophils (rat anti-mouse, diluted 1/200; Serotec, Oxford, UK), NG2 chondroitin sulfate proteoglycan (pericytes, rabbit anti-rat, diluted 1/200; Chemicon, Temecula, CA), CD11b/TRITC (rat antimouse, diluted 1/50; Pharmingen, San Diego, CA), $\alpha$-smooth muscle actin/FITC (mouse monoclonal, diluted 1/200; Sigma-Aldrich), $\alpha$-smooth muscle actin/Cy3 (mouse monoclonal, diluted 1/1000; Sigma-Aldrich) were incubated for 1 hour at room temperature. After washings, the appropriate secondary antibodies conjugated to FITC and Texas Red were applied, swine anti-rabbit (diluted 1/40; Dakopat, Glostrup, Denmark), mouse antiguinea pig (diluted 1/40; Sigma), and goat anti-rat (diluted 1/100; Molecular Probes, Eugene, OR), for 30 minutes.

For immunolabeling revealed with AEC systems, the sections were incubated for 1 hour at room temperature with primary Ab, PECAM (rat anti-mouse, diluted 1/250; Pharmingen), neutrophils (rat anti-mouse, diluted 1/200; Serotec), and F4/80 macrophages (rat anti-mouse, diluted 1/300; Serotec), and then incubated with secondary Ab rabbit anti-rat/biotin (diluted 1/400; DAKO, Glostrup, Denmark). The revelation was performed with AEC staining after the incubation of streptavidin/horseradish peroxidase (diluted 1/500; DAKO) for 30 minutes.

For quantitative measurement of host cell infiltration in the collagen gel, automatic computer-assisted image analysis was performed on images obtained after bisbenzimide staining and immunolabeling of inflammatory cells or mesenchymal cells. The ratio between the surface of bisbenzimide staining and the surface of specific immunostaining was measured by using Aphelion 3.2 software (Adsis, Meythet, France).

\section{In Situ Hybridization Analysis: Y-Chromosome Detection}

Smears of BM and peripheral blood were fixed with acetone for 10 minutes at $4^{\circ} \mathrm{C}$, with Carnoy's fixative $(3: 1$, methanol/acetic acid) at $4^{\circ} \mathrm{C}$ for 10 minutes, washed, and fixed in formaldehyde $1 \%$ at $4^{\circ} \mathrm{C}$ for 1 minute. The slides were dehydrated, denatured in $70 \%$ formamide/2X standard saline citrate buffer at $72^{\circ} \mathrm{C}$ for 5 minutes, quenched in ice-cold $70 \%$ ethanol, and air-dried. The FITC Y-painting chromosome probes (Cambio, Cambridge, UK) were denatured at $65^{\circ} \mathrm{C}$ for 10 minutes, incubated for 30 minutes at $37^{\circ} \mathrm{C}$ hybridization, and were added on each slide for overnight incubation at $37^{\circ} \mathrm{C}$. Slides were washed in $2 \times$ standard saline citrate $/ 0.3 \%$ Tween 20 , first at $72^{\circ} \mathrm{C}$ and then at room temperature. After dehydration, slides were mounted with Vectashield medium containing propidium iodide (Vector Laboratories, Peterborough, UK).

\section{Colony-Forming Unit Assay: CFU-Cs}

Total BM cells $\left(2 \times 10^{4}\right.$ cells $)$ and blood cells $\left(2 \times 10^{5}\right.$ cells) were plated in $35-\mathrm{mm}$ suspension culture dishes containing $1.1 \mathrm{ml}$ of $1 \%$ methylcellulose [Methocult (StemCell Technologies) containing 15\% fetal bovine serum, $1 \%$ bovine serum albumin, $10 \mu \mathrm{g} / \mathrm{ml}$ human insulin, $200 \mu \mathrm{g} / \mathrm{ml}$ human transferrin, $10^{-4} \mathrm{~mol} / \mathrm{L}$ 2-mercaptoethanol, $2 \mathrm{mmol} / \mathrm{L}$ L-glutamine, $50 \mathrm{ng} / \mathrm{ml}$ mouse stem cell factor, $10 \mathrm{ng} / \mathrm{ml}$ mouse interleukin (IL)-3, $10 \mathrm{ng} / \mathrm{ml}$ human IL-6, and $3 \mathrm{U} / \mathrm{ml}$ human erythropoietin]. Scoring of CFU-C (CFU-GM, BFU-E, and CFU-Mix) was performed on day 10 with an inverted microscope.

\section{Transmission Electron Microscopy}

Transplants were fixed in $2.5 \%$ glutaraldehyde- 0.15 $\mathrm{mol} / \mathrm{L}$ cacodylate buffer, postfixed in $2 \%$ aqueous osmium tetroxide, dehydrated in a graded series of ethanol, and embedded in Epon. Transplants were sectioned perpendicular to the gel surface. Ultrathin sections were contrasted with uranyl acetate and lead citrate before examination with a Jeol (Tokyo, Japan) CX100 electron microscope at $60 \mathrm{kV}$.

\section{Statistical Analysis}

Data were analyzed with GraphPad Prism 4.0 (San Diego, CA). The Mann-Whitney test or $\chi^{2}$ test were used to determine whether differences between experimental groups could be considered as significant $(P<0.05)$. 

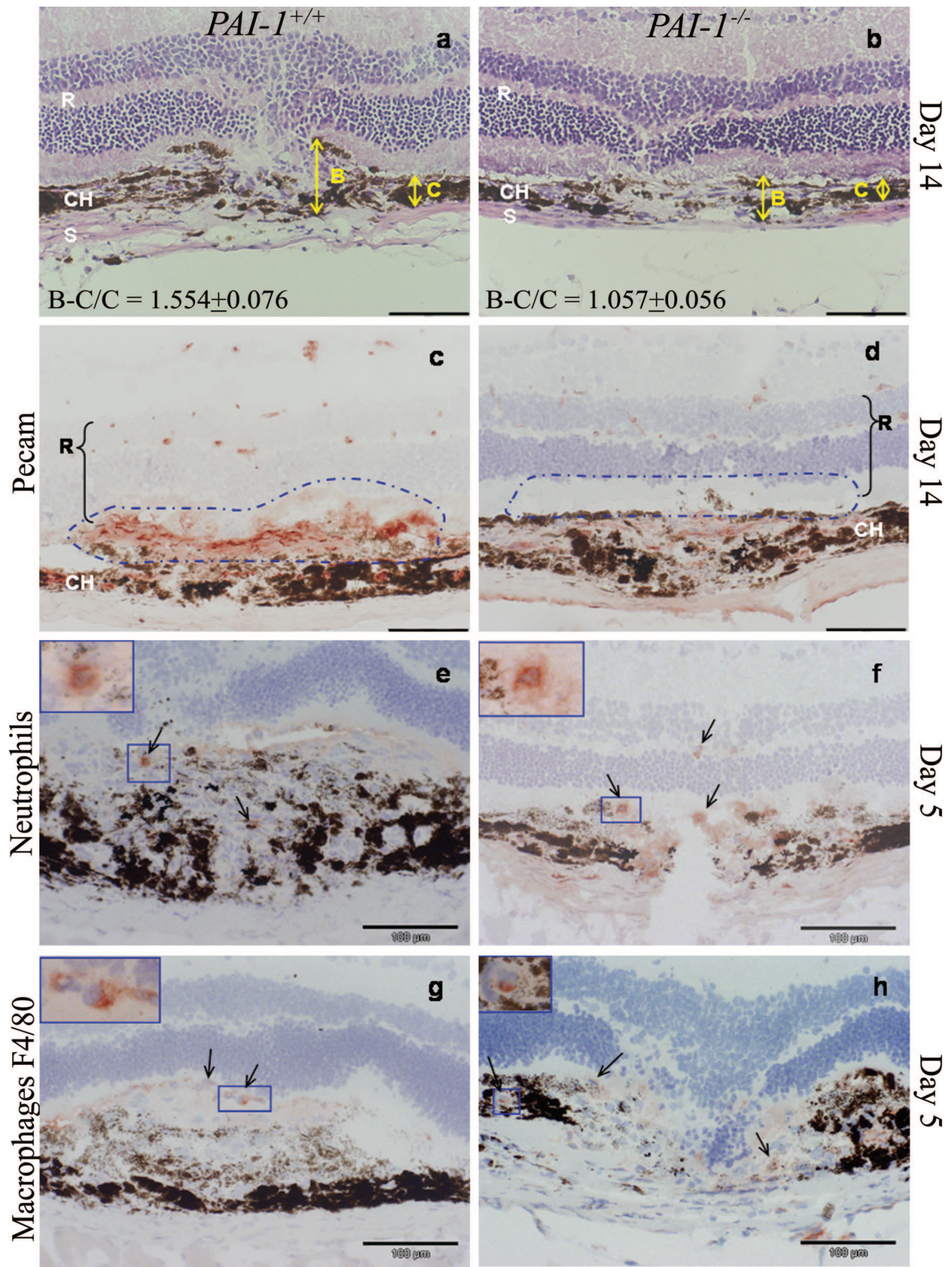

Figure 1. Histopathological analysis of laser-induced CNV. Sections of eyes resected from $P A I-1^{+/+}$mice $(\mathbf{a}, \mathbf{c}, \mathbf{e}$, and $\mathbf{g})$ and $P A I-1^{-/-}$mice $(\mathbf{b}, \mathbf{d}, \mathbf{f}$, and $\mathbf{h})$ were stained with H\&E (a and b), or immunostained with antibodies raised against endothelial cells (anti-PECAM, $\mathbf{c}$ and $\mathbf{d}$ ), neutrophils (e and $\mathbf{f}$ ), or macrophages ( $\mathbf{g}$ and $\mathbf{h}$ ). Sections were prepared at days $5(\mathbf{e}-\mathbf{h})$ or $14(\mathbf{a}-\mathbf{d})$ after laser injury. The neural retina (R), choroidal layer (Ch), and sclera (S) are indicated. The double arrows (yellow) delineate the total thickness from the bottom of choroids to the top of lesion (B) and the thickness of adjacent normal choroid (C) that are used for quantitative analysis in Figure 2. $\mathbf{c}$ and d: Vessels are growing in the subretinal space (dotted line). e-h: Positive cells are delineated by arrows and are showed in insets. Scale bars $=100 \mu \mathrm{m}$. 


\section{Results}

\section{BM Transplantation}

WT $\left(P A l-1^{+/+}\right)$and PAl-1-deficient $\left(P A /-1^{-1-}\right)$ mice were irradiated and transplanted with unfractionated $\mathrm{WT}$ or PAl-1 ${ }^{-1-}$ BM. Five weeks after BM transplantation (ie, after allowing for BM reconstitution), laser burns were performed to induce CNV, or malignant keratinocytes were transplanted. Genotyping of spleen and liver was performed for all animals. In addition, success of BM transplantation was assessed by two different approaches. First, BM from GFP transgenic mice was transplanted into irradiated WT or PAI-1 $1^{-1-}$ mice, and flow cytometry was performed on peripheral blood and BM. Second, irradiated female animals (WT or PAl-1 ${ }^{-1-}$ ) were transplanted with BM harvested from tibia and femur of male mice (WT or PAl-1 ${ }^{-1-}$ ). BM-derived male cells were detected in BM and blood by using in situ hybridization for Y-chromosome DNA. A similar percentage of BM reconstitution (70 to $80 \%$ ) was observed with these two approaches. Interestingly, the lack of PAI-1 in either the recipient or the donor cells did not affect the proportion of BM reconstitution. In addition, functionality of BM-derived stem cells was identical in different groups of mice engrafted or not as assessed by colony-forming unit assay (data not shown).

\section{CNV}

Photocoagulation with an argon laser induced trauma leading to CNV under retina similar to that observed in agerelated macular degeneration. Damage and neovascularization were estimated by measuring, on serial sections, the maximal height of lesion (B) above the thickness of the normal choroid observed in neighboring intact zones (C). Two weeks after laser burns, WT mice showed typical mushroom-like areas of CNV characterized by a B-C/C ratio of $1.544 \pm 0.076$. In $P A /-1^{-1-}$ mice the neovascular reaction was much more restricted with a $\mathrm{B}-\mathrm{C} / \mathrm{C}$ ratio of $1.057 \pm$ 0.056 ( $P<0.001$ ) (Figure 1, a and b). Histological immunostainings with anti-PECAM (Figure 1, $c$ and d) confirmed the presence of newly formed blood vessels in $P A /-1^{+/+}$ mice, but not in $\mathrm{PAl}-1^{-1-}$ mice, as previously described. ${ }^{10}$ To identify cells infiltrating lesions, immunohistochemical analysis was performed at different time points after laserinduced CNV. Inflammatory cell infiltrates were rapidly observed in both mouse genotypes as assessed by immunostaining using anti-neutrophil (Figure 1, e and f) and antimacrophage (F4/80) antibodies (Figure 1, g and h). At days 3, 5, and 7 after laser burns, neutrophils and macrophages were detected in CNV. Quantification of inflammatory cell number reveals no significant difference between genotypes (count of neutrophils per slide: $1.54 \pm 0.42$ in PA/$1^{-l-}$ mice and $1.56 \pm 0.31$ in WT mice, $P=0.98$; count of macrophages F4/80 per slide: $1.62 \pm 0.53$ in $P A / 1^{-1-}$ mice and $0.94 \pm 0.55$ in WT mice, $P=0.16$ ) (Figure 1). These inflammatory cells were no longer detected at day 14 . Therefore, these data clearly demonstrate the recruitment of inflammatory cells and endothelial cells in laser-induced choroidal lesions.

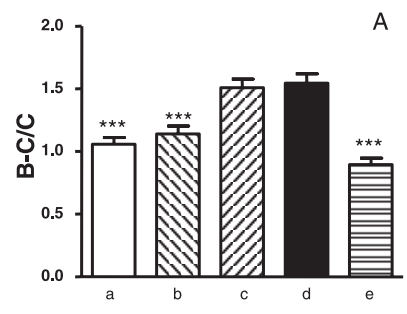

Recipient PAl-1\% PAl-1\% PAl-1\% PAl-1+// PAl-1+/4

Figure 2. Effect of BM transplantation on CNV observed at day 14 after laser injury. Quantification of lesion was performed by analyzing histological section (A) and volume of $\mathrm{CNV}$ on choroidal flatmounts (B). PAI-1 ${ }^{-1-}$ mice were not grafted (a) or transplanted with BM from $P A I-1^{-1-}$ mice $(\mathbf{b})$ or with $\mathrm{BM}$ from $P A I-1^{+/+}$mice $(\mathbf{c})$. $P A I-1^{+/+}$mice were not grafted (d) or grafted with BM from $P A I-1^{-1-}$ mice $(\mathbf{e})$. The $\mathrm{B}-\mathrm{C} / \mathrm{C}$ ratio was determined by computer-assisted image analysis as described in Materials and Methods (see also legend of Figure 1). Number of animals per experimental group: $n=8$ with four impacts per eye, ie, 64 lesions. ${ }^{*} P<0.05 ;{ }^{* * *} P<0.005$ compared with control $P A I-1^{+/+}$mice $(\mathbf{d})$.

We next investigated whether the transplantation of $P A /-1^{+/+}$BM could restore the impaired CNV observed in mutated mice. The $\mathrm{BM}$ of irradiated $P A /-1^{-1-}$ mice were reconstituted with $\mathrm{BM}$ extracted from $\mathrm{PAl}-1^{+/+}$ mice ( $n=8$, ie, 64 lesions) or $P A /-1^{-1-}$ mice $(n=8$, ie, 64 lesions) as a control, and mice were subjected to laser. CNV was quantified by measuring different parameters: $(\mathrm{B}-\mathrm{C}) / \mathrm{C}$ ratio determined on tissue section (Figure 2A) and volume of CNV on choroidal flatmounts (Figure 2B) observed by confocal microscopy. ${ }^{19} \mathrm{~A}$ complete restoration of neovascularization was observed in PAl-1 ${ }^{-1-}$ mice engrafted with WT (Figure 2). In sharp contrast, choroidal lesion was smaller in PA/$1^{-1-}$ mice transplanted with $P A /-1^{-1-} \mathrm{BM}(P<0.005)$ and similar to that observed in control $P A /-1^{-1-}$ mice (Figure 2). Interestingly, the engraftment of PAl-1-deficient BM into WT mice decreases significantly the CNV in comparison to WT control mice ( $n=4$, ie, 32 lesions) $(P<0.005)$ (Figure 2).

To visualize spatial and temporal distribution of BMderived cells in laser-induced lesions, BM from GFP transgenic mice was engrafted into control C57BL/6 WT mice $(n=4), P A l-1^{+/+}(n=8)$, and PAl-1 $1^{-1-}(n=$ 8) mice. At different time points after laser injury, flatmount preparations of eyes were analyzed by confocal microscopy (Figure 3, A-F). Vessels were concomitantly visualized in red by injecting dextran-TRITC. $\mathrm{GFP}^{+}$cells were visualized in all lesions and were never detected in the neighboring intact chorioretinal areas. At day 3, isolated cells positive for GFP were abundant in CNV lesions, in contrast to normal unlesioned choroids (Figure 3A). This cell recruitment precedes the neoformation of vessel since at this time point, no vessel structure was identified by dextranTRITC injection. At days 5 and 7, both isolated cells and vessel-associated cells were GFP labeled (Figure 3, B and C). A substantial proportion of GFP-positive cells was not directly associated to vessel structures (75.30\%, range 60 to $82 \%)$. Some $\mathrm{GFP}^{+}$cells closely apposed to and covered neovessels (Figure 3, E and F). Occasionally, GFP-positive cells were found incorporated into newly formed vessels (Figure 3E). Immu- 

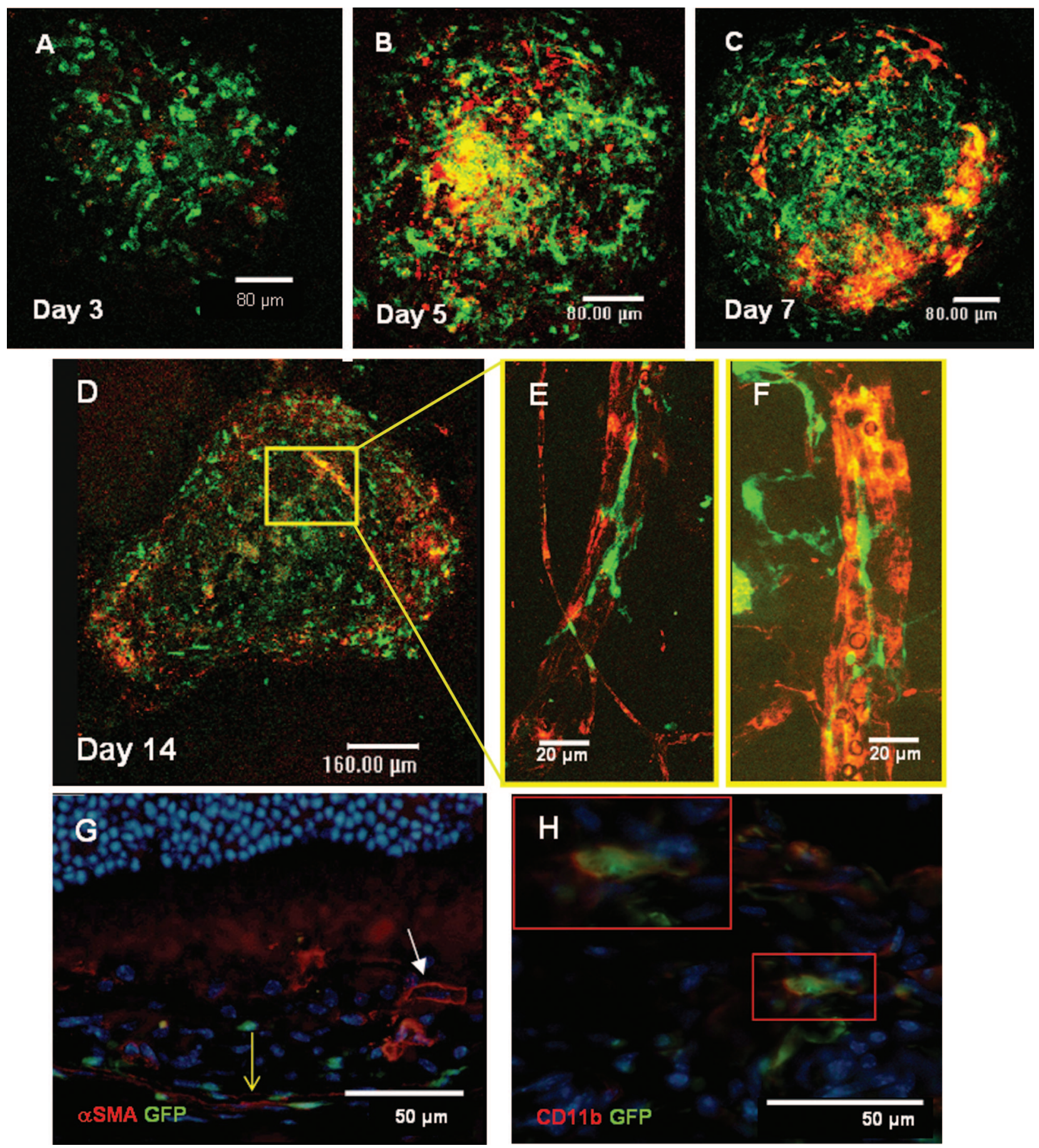

Figure 3. Confocal visualization of flatmount choroids and co-localization on histological sections. PAI-1 ${ }^{+/+}$mice were transplanted with BM from GFP transgenic mice. At days $3(\mathbf{A}), 5(\mathbf{B}), 7(\mathbf{C})$, and $14(\mathbf{D}-\mathbf{F})$ after laser injury, mice were intravenously injected before sacrifice with rhodamine-conjugated dextran. Captured red and green channel digital images of flat-mounted choroids were merged. A-D: Reconstruction of all sections through a whole mount. Vascular structures (red and yellow) were visible from day 5 until day 14 . E and F: Higher magnifications of the structure delineated in $\mathbf{D}$ by a square. GFP-positive cells (in green) were either separated from vessels labeled in red, were lining vessels, or occasionally incorporated in vessels. G and $\mathbf{H}$ : Immunostaining of sections of choroidal lesions counterstained with bisbenzimide (blue staining). Immunostainings reveal that GFP migrated cells were not associated with $\alpha$-SMA staining (red) (G) but were associated with CD11b staining (red) (H). G: $\alpha$-SMA-positive cells are delineated by yellow arrow, and white arrow designates blood vessel structures. H: GFP-positive inflammatory cells are showed in insets. Scale bars: $20 \mu \mathrm{m}(\mathbf{E}$ and $\mathbf{F}) ; 50 \mu \mathrm{m}(\mathbf{G}$ and $\mathbf{H}) ; 80 \mu \mathrm{m}(\mathbf{A}-\mathbf{C}) ;$ or $160 \mu \mathrm{m}(\mathbf{D})$.

nohistochemical staining of choroidal lesion revealed that GFP-positive cells were not associated with $\alpha$-smooth muscle actin labeling (Figure 3G). In contrast, GFP positivity co-localized with CD11b staining, identifying BM-derived cells as inflammatory cells (Fig- ure $3 \mathrm{H}$ ). Similar recruitment and localization of BMderived cells were observed in both $P A /-1^{+/+}$and $P A /-$ $1^{-1-}$ mice. These results demonstrate that BM-derived cells are sufficient to restore the vascularization impaired by PAl-1 deficiency. 


\section{Malignant Keratinocyte Transplantation}

To determine whether BM-derived cells could restore the impaired vascularization observed in the absence of PAl-1, in other pathological conditions, we have used a model of skin tumor transplantation as previously described. $7,8,16$ Mouse malignant PDVA keratinocytes precultured on a collagen type I gel were covered by a silicone chamber and transplanted in toto onto the back muscle fascia of mice. ${ }^{15}$ The grafted cells rapidly developed into highly proliferating stratified epithelia, and collagen gel was gradually replaced by a highly vascularized granulation tissue. Three weeks after transplantation, new blood vessels invaded the collagen gel in PA/$1^{+/+}$mice, reached malignant epithelial layer and were associated to stromal septa of invading tumors (Figure 4D). In sharp contrast, blood vessels failed to migrate in $P A l-1^{-1-}$ mice and remain in host tissue, below the collagen gel (Figure 4E). ${ }^{7}$

To better identify host cells involved in such invasive and angiogenic process, we performed a histological analysis of tumor samples at 1 week and 3 weeks after tumor transplantation (Figure 4). At each time point ( $n=$ 10), we observed an infiltration of inflammatory cells stained with antibodies recognizing myelomonocytic cells (anti-CD11b) (Figure 4, F and G) or neutrophils (Figure 4, $\mathrm{H}$ and I). Cells positive for $\alpha$-smooth muscle actin ( $\alpha$-SMA) (myofibroblastic cells) were rarely observed at week 1 but were abundant at week 3 (Figure 4, $\mathrm{J}$ and $\mathrm{K}$ ). Such an infiltration of host cells was evidenced both in PAl-1 ${ }^{+/+}$and PAl-1 ${ }^{-/-}$mice. Quantitative assessment of host cell infiltration was performed by computerassisted image analysis. Interestingly, a twofold reduction of $\alpha$-SMA-positive cell infiltration was observed in PAl- $1^{-1-}$ mice (percentage of $\alpha$-SMA positivity, $19.19 \pm$ 1.9 in WT mice versus $10.73 \pm 2.3$ in deficient mice; $P<$ 0.05). In sharp contrast, although fewer inflammatory cells appeared to infiltrate the collagen gel in $\mathrm{PAl-1}{ }^{-1-}$ mice, the proportion of each cell type was not influenced by the genotype. Indeed, in both experimental groups, identical ratios were obtained between bisbenzimide staining and immunolabeling for anti-CD11b (percentage of specific immunostaining, $21.76 \pm 5.1$ in WT mice versus $24.47 \pm 6.5$ in deficient mice) or anti-neutrophils (percentage of specific immunostaining, $22.08 \pm 3.4$ in WT mice versus $14.26 \pm 1.8$ in deficient mice). Electron microscopic analysis corroborated the presence of inflammatory, endothelial, and fibroblastic cells in collagen gel in both WT and mutated mice (Figure 4, A-C).

Because inflammatory cells and endothelial cells seemed to be the major types of infiltrating cells, BM engraftment was performed to determine the origin of critical cells whose lack of PAl-1 led to impaired vascularization and invasion. When malignant keratinocytes were transplanted into PAl-1 ${ }^{-1-}$ mice engrafted with PAI$1^{+/+} \mathrm{BM}$, none of the animals developed vascularized tumors (score 0 in $100 \%$ mice, $n=10$ ) (Figure 5B). Thus, the angiogenic and invasive phenotypes were similar to those observed in control PAl-1-1- mice (Figure 4E) or in $P A l-1^{-1-}$ mice engrafted with $P A I-1^{-1-} \mathrm{BM}$ (Figure $5 \mathrm{C}$ ) and distinct to that of $\mathrm{PAl}-1^{+/+}$mice (Figure $5 \mathrm{~A}$ ). The presence of functional engrafted $\mathrm{PAl}-1^{+/+} \mathrm{BM}$ cells in the grafted mice was assessed by the presence of PAI-1positive cells in their spleen (data not shown). In contrast, the engraftment of $P A /-1^{-1-} \mathrm{BM}$ in $\mathrm{PAl}-1^{+/+}$mice did not affect the vascularization observed usually in WT mice (Figure 5D). The recruitment of BM-derived cells in tumors was next investigated by grafting C57BL/6 WT mice with BM from GFP transgenic mice. Few GFP ${ }^{+}$cells were visualized in the tumor transplants, but their detection was restricted to the tumor-host interface (Figure 5E).

These data suggest that, in contrast to CNV, BM cells are not sufficient to restore impaired tumor vascularization and invasion in the transplantation system. The importance of local host cells infiltrating the collagen gel was then investigated by transferring tumor transplants from PAl- $1^{+/+}$mice to PAl-1 $1^{-/-}$mice (Figure 6). PDVA cells precultured on a collagen gel were transplanted into $P A /-1^{+/+}$or to $P A /-1^{-1-}$ mice. One week later, tumor transplants were harvested and transferred into $P A /-1^{+/+}$ or to $P A /-1^{-1-}$ mice, and tumors were led to grow for 3 additional weeks. As controls, PDVA cells were transplanted for 3 consecutive weeks into $P A /-1^{+/+}$or to PAI$1^{-1-}$ mice. An invasive and angiogenic phenotype (scores + or ++ ) was observed in $100 \%$ of tumors transplanted for 3 consecutive weeks into PAl- $1^{+/+}$mice (Figure $6 \mathrm{e}$ ) and in $80 \%$ of tumors transplanted for 1 week into $P A /-1^{+/+}$mice and then transferred for 3 weeks in $P A /-1^{+/+}$mice (Figure $\left.6 \mathrm{~d}\right)(n=5)$. None of the tumors were invasive or vascularized (score 0 in $100 \%$ animals) after transplantation into $P A /-1^{-1-}$ mice for 3 weeks (Figure $6 \mathrm{a}$ ) or after transfer from $\mathrm{PAl}-1^{-1-}$ mice to $\mathrm{PAI}-1^{-1-}$ mice (Figure 6b) $(n=5)$. Interestingly, a restoration of tumor invasion and vascularization was observed in $37.5 \%$ of tumors transplanted for 1 week into PAl- $1^{+/+}$ mice and then transferred into $P A /-1^{-1-}$ mice (Figure $6 \mathrm{c}$ ) $(n=8)$. This demonstrates the essential contribution of resident host $\mathrm{PAl}-1^{+/+}$cells infiltrating the collagen gel during the first week of transplantation.

\section{Discussion}

PAl-1-deficient mice cannot support neovascularization when challenged with malignant keratinocytes or laserinduced choroidal lesions. ${ }^{8,10}$ We provide for the first time evidence that two distinct processes of pathological neovascularization controlled by PAI-1 involve different responses of BM-derived cells to angiogenic stimuli. Key contribution of BM-derived cells in CNV is demonstrated by the impaired vascularization in WT mice grafted with $P A /-1^{-1-}$ BM and the rescue of CNV pattern in deficient mice by WT BM-derived cells. We have previously reported that CNV formation in PAl-1-deficient mice can be restored when systemic and local PAI-1 expression was achieved by injection of recombinant protein ${ }^{20}$ or replication-defective adenovirus bearing human PAI-1 cDNA. ${ }^{10}$ The present data indicate that BM-derived cells can deliver PAl-1 to choroidal lesions. Conversely, the crucial involvement of host cells distinct from BM cells in skin carcinomas is supported by the restoration of tumor invasion and vascularization after transfer of tumor trans- 


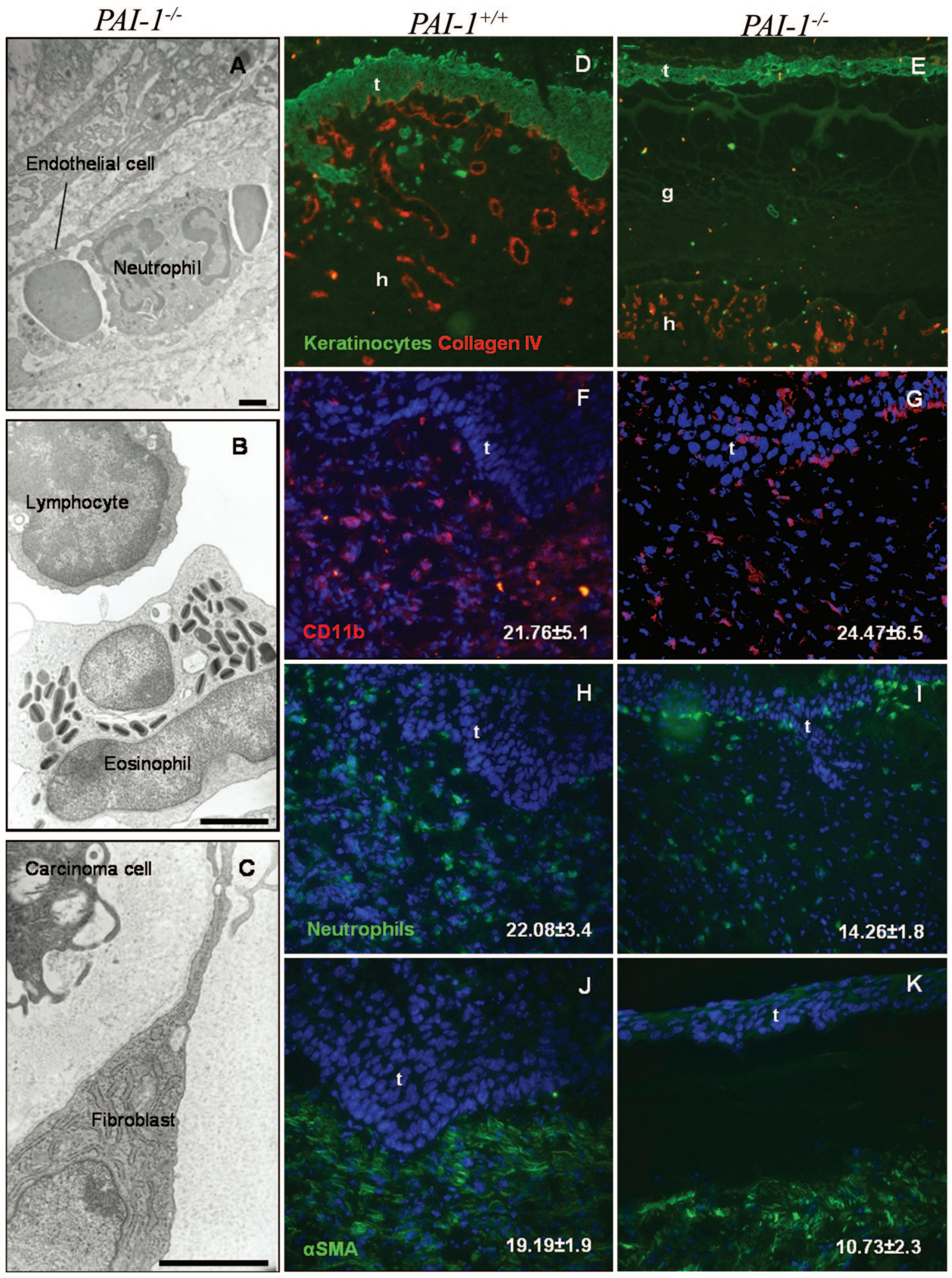

Figure 4. In vivo invasive and angiogenic behavior of tumor cells. Malignant PDVA cells precultured on a collagen gel were transplanted into $P A I-1^{-/-}$mice or WT mice. Electron microscopic analysis of tumor transplants after 1 week reveals infiltration of gel by neutrophils, endothelial cells (A), eosinophils and lymphocytes $(\mathbf{B})$, and fibroblasts $(\mathbf{C})$. Similar cell types were identified in $P A I-1^{+/+}$(data not shown) and $P A I-1^{-/-}$mice. Immunohistological analysis of tumor 3 weeks after the transplantation into $P A I-1^{+/+}$mice $(\mathbf{D}, \mathbf{F}, \mathbf{H}$, and $\mathbf{J})$ or $P A I-1^{-/-}$mice $(\mathbf{E}, \mathbf{G}, \mathbf{I}$, and $\mathbf{K})$. Sections were immunostained with antibodies raised against tumor cells (green, anti-keratin) and blood vessels (red, anti-type IV collagen of blood vessel basement membrane) (D and $\mathbf{E}$ ), inflammatory cells (anti-CD11b) (F and $\mathbf{G}$ ), neutrophils ( $\mathbf{H}$ and $\mathbf{I}$ ), or $\alpha$-SMA ( $\mathbf{J}$ and $\mathbf{K})$. t, tumor; g, collagen gel; h, host tissue. F-K: Sections were counterstained with bisbenzimide (blue staining). Numbers indicate the percentage of positivity assessed by computer-assisted image analysis. Scale bars $=2 \mu \mathrm{m}$. Original magnifications: $\times 200$ $(\mathbf{D}$ and $\mathbf{E}) ; \times 400(\mathbf{F}-\mathbf{K})$. 

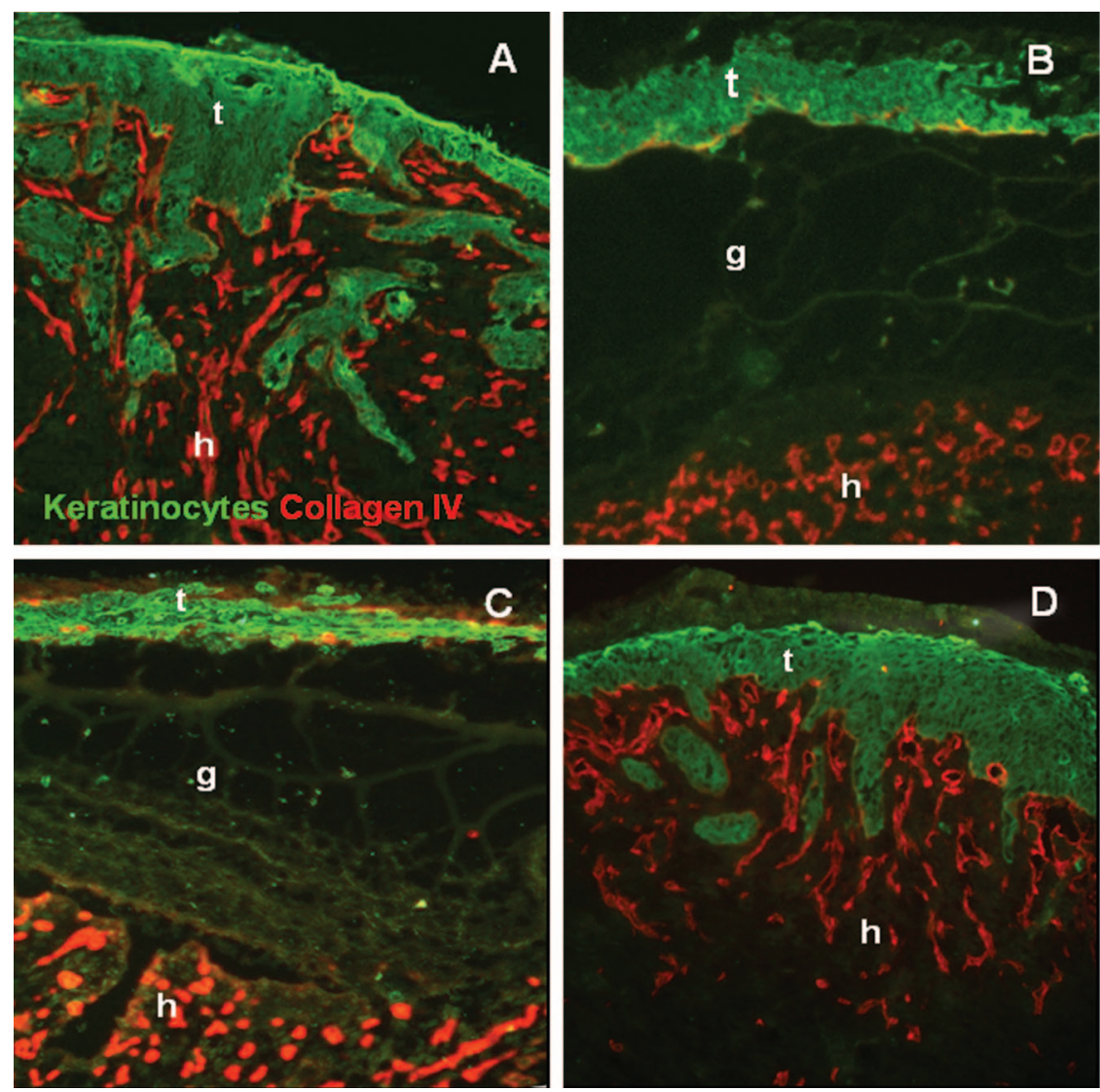

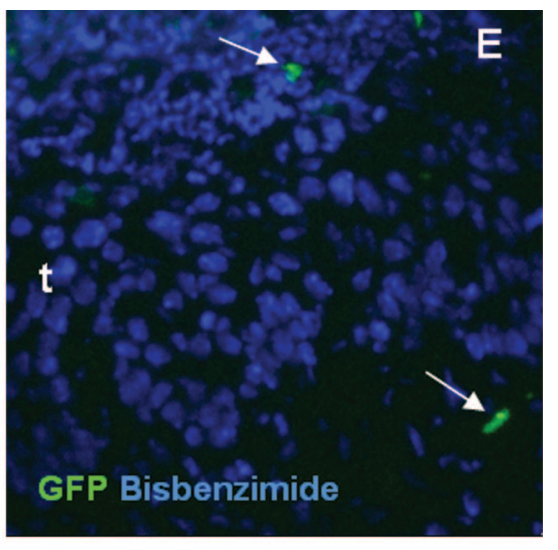

Figure 5. Invasive and angiogenic behavior of PDVA cells transplanted into mice. Tumor cells were transplanted into $P A I-1^{+/+}$mice $(\mathbf{A}), P A I-$ $1^{-/-}$mice engrafted with BM from WT mice $(\mathbf{B})$. $P A I-1^{-1-}$ mice engrafted with BM from $P A I-1^{-1}$ mice $(\mathbf{C}), P A I-1^{+/+}$mice engrafted with $\mathrm{BM}$ from $P A I-1^{-/}$mice (D), C57BL/6 WT mice engrafted with BM from GFP mice (E). A-C: Malignant cells were detected by using anti-cytokeratin $\mathrm{Ab}$ (green), and vessels were detected using an anticollagen type IV Ab (red). The simultaneous use of two control groups, ie, $P A I-1^{-/-}$and $P A I-1^{+/+}$ mice that were not irradiated and engrafted led to similar phenotypes to that obtained previously (A and B). E: GFP-positive cells were evidenced at the tumor-host interface; sections were counterstained with bisbenzimide (blue staining). $t$, tumor; g, collagen type I gel; h, host connective tissue. Original magnifications: $\times 200(\mathbf{A}-\mathbf{D}) ; \times 400$ (E) plants from $P A l-1^{+/+}$mice to $P A /-1^{-1-}$ mice, whereas $B M$ transplantation failed to circumvent the angiogenic defect observed in mutant mice. To the best of our knowledge, this report provides first experiment evidence for a key role played by BM-derived PAI-1 in pathological ocular vascularization. In addition, it identifies PAI-1 as an important molecular determinant of the seed and soil theory proposed by Paget. ${ }^{21}$

Our findings support the concept that BM-derived cells participate in CNV formation as recently reported by several groups, ${ }^{18,22,23}$ thus offering new potential targets for the development of anti-angiogenesic therapies. In addition, we demonstrate, for the first time, that BM-derived cells producing PAI-1 are essential actors of CNV formation. In support of this new concept is the evidence that CNV formation was impaired in WT mice grafted with PAl- $1^{-1-}$ BM. Of great interest is also our finding that WT BM-derived cells can rescue the defective CNV pattern observed in PAl-1-deficient mice. These data demonstrate that CNV formation was dependent to the PAI-1 status of BM-derived cells and not to that of resident endothelial cells. The incapacity of BM-derived cells issued from $P A /-1^{-1-}$ mice to rescue impaired vascularization could not be ascribed to a defect of BM reconstitution as assessed by detection of male (Y-chromosome DNA-positive) donor cells in female recipient mice as well as by functional CFU-C assay.

The main proportion of BM-derived cells was not incorporated into vessel structure and importantly was recruited at early phases of CNV formation before detection of any vessel (at day 3). Immunohistochemical analysis revealed the presence of neutrophils and macrophages from days 3 to 7 . GFP positivity co-localized with CD11b staining. The present study does not strongly support the recruitment of BM-derived cells into CNV. It provides evidence that BM-derived cells are active players of CNV mainly by contributing to the inflammatory response rather than by providing endothelial cell progenitor. These observations are consistent with the demonstration that in a mouse model of hindlimb ischemia (arteriogenesis and angiogenesis), BM-derived cells do not promote vascular growth by incorporating into vessel walls but may function as supporting cells. ${ }^{24}$

In sharp contrast, in our tumor transplant model, BMderived cells could be mobilized at the tumor-host interface but did not compensate for the inability of neighboring PAl-1-deficient endothelial cells to form new vessels and did not incorporate into tumor vasculature. Although BM-derived cells can contribute to tumor neoangiogenesis in several experimental models, ${ }^{12,25}$ their contribution does not seem universal. ${ }^{26-29}$ For instance, BM cells did not appreciably contribute to the vasculature of murine gliomas ${ }^{30}$ and stem cells have been reported to contribute to human tumor endothelium at low levels averaging only $4.9 \% .{ }^{31}$ Altogether, these data suggest that the contribution of BM precursors to tumor vessel formation may be dependent on the steps of tumor progression and on the tumor types. ${ }^{24,32,33}$

Tumor angiogenesis and invasion involve complex interactions occurring between tumor cells and different 


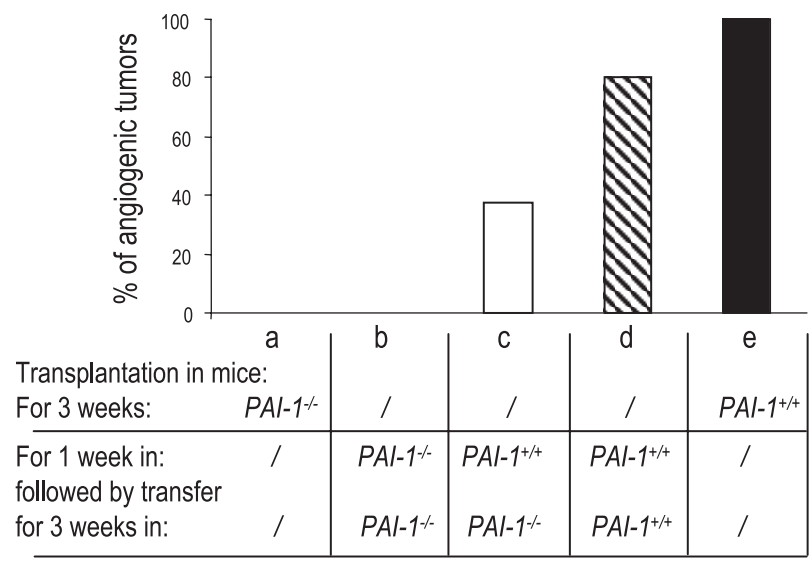

Figure 6. Analysis of the invasive and angiogenic phenotype of tumors transplanted into $P A I-1^{+/+}$or $P A I-1^{-/-}$mice. Malignant PDVA cells cultured on a collagen gel and protected by a chamber were transplanted into $P A I-1^{-/-}$mice (b) or to PAI-1 ${ }^{+/+}$mice (c and $\mathbf{d}$ ) for 1 week, and then the whole transplantation chambers were harvested and transferred to PAI-1 $1^{-1-}$ (b and c) or $P A I-1^{+/+}$(d) mice for 3 additional weeks. As controls, cells were transplanted into $P A I-1^{-/-}$(a) or $P A I-1^{+/+}$(e) mice for 3 weeks. Results represent the percentage of angiogenic tumors as described in Materials and Methods

host cell types, such as endothelial cells, inflammatory cells, and fibroblasts. Most inflammatory cells (macrophages, monocytes, neutrophils, mast cells) produce proteases and secrete cytokines, chemokines, and growth factors essential for extracellular matrix remodeling, cell migration, and angiogenesis. ${ }^{34,35}$ The detection of only few cells derived from the BM of GFP transgenic mice in tumor transplants indicates that local vascular cells contribute more to tumor progression than BM-derived cells, in this model of skin carcinoma. Our data demonstrate that the infiltration of transplanted matrix by PAI-1-producing host cells during the first week of transplantation is sufficient to rescue tumor invasion and vascularization after transfer into PAI-1 ${ }^{-1-}$ mice. Thus, local host cells infiltrating the collagen gel during the early phase of tumor transplantation are essential for tissue remodeling and to create a permissive soil for tumor invasion and vascularization. During tumor growth, stromal activation is an early event with rapid progression of blood vessels and stromal cells toward the tumor layer. This host reaction precedes tumor cell invasion into the surrounding tissue. ${ }^{36}$ Therefore, the skin malignant keratinocyte layer observed in PAl-1 ${ }^{-1-}$ mice could not be ascribed to differential rejection of tumor transplant ${ }^{8,17,36}$ but rather reflects an impaired stromal reaction and vascularization in the absence of PAl-1, a prerequisite for tumor invasion. ${ }^{36,37}$ The present study identifies PAI-1 as a molecular determinant of the seed and soil hypothesis of Paget. $^{21}$

PAI-1 can be produced by various host cells including inflammatory cells, endothelial cells and myofibroblasts. Immunohistochemical analysis and electron microscopy revealed the presence of inflammatory cells, fibroblasts and endothelial cells in this transplanted collagen gel. Quantitative measurement of host cell infiltration showed a reduction of $\alpha$-SMA-positive cells in PAl-1-1- mice, whereas inflammatory cell recruitment was identical in both genotypes. An intriguing possibility to consider in our tumor model is the cooperation between inflammatory cells and resident host cells (endothelial cells and/or fibroblasts). In this context by using this tumor transplantation model, we have previously demonstrated the key role played by two gelatinases, MMP-2 produced by mesenchymal cells and MMP-9 secreted by neutrophils. ${ }^{38}$ Indeed, although the single deficiency of MMP-2 or MMP-9 did not affect tumor cell invasion and vascularization, their combined deficiency abolished the invasive and angiogenic phenotype of malignant keratinocytes.

Our previous studies have emphasized similarities between the molecular mechanisms of PAl-1 action in CNV and tumor vascularization. A dose-dependent effect of PAI-1 has been evidenced, PAl-1 being proangiogenic at low concentrations and anti-angiogenic at supraphysiological doses. ${ }^{16,20} \mathrm{PAl}-1$ is known to control uPA-dependent plasmin generation, and therefore it may control extracellular matrix degradation and growth factor and/or cytokine/chemokine activation. In addition, PAl-1 can interfere with integrin binding to tissue vitronectin, thereby influencing cell migration. ${ }^{39,40}$ By using recombinant proteins and/or adenoviral-mediated transfer of mutated forms of PAI-1, we clearly demonstrated previously that the contribution of PAI-1, in both pathological processes, is related to its capacity to control plasmin-mediated proteolysis rather than by interacting with vitronectin. ${ }^{8,20}$ Analysis of endothelial cell sprouting from $P A /-1^{-1-}$ aortic fragments corroborated this molecular mechanism of PAI-1 action. ${ }^{41}$ Although extracellular proteolysis is required for cell migration, an excess of proteolysis would impair the presence of a permissive substrate for cell migration. Through its capacity to control plasmin-mediated proteolysis, PAI-1 may tightly control proteolytic events associated with cell migration. ${ }^{16,20,41}$ Both a defect and an excess of PAI-1 levels led to impaired vascularization of laser-induced choroidal lesions ${ }^{20}$ and of tumor transplants. ${ }^{16}$ It is worth noting that recent reports demonstrate the requirement of proteolytic enzyme such as cathepsin $\mathrm{L}^{42}$ and $\mathrm{UPA}^{43}$ for the migration of BMderived cells such as endothelial progenitor cell. The function of PAl-1 could therefore consist in the protection of migrating cells by preventing excessive pericellular proteolysis and/or cellular damage. Despite molecular similarities, between the two PAI-1-controlled vascularization processes, the present study demonstrates for the first time that different cellular mechanisms contribute to PAl-1-regulated neovascularization in these two models. Our study sheds new lights on what role individual PAI1-producing cells play in the pathogenesis of CNV and cancer.

In conclusion, the two processes of pathological vascularization studied here are both dependent to PAI-1 levels. The present study indicates that BM-derived cells are essential to deliver PAl-1 to CNV, but not to skin transplanted carcinomas. It gives new insight into the respective roles of circulating and resident cells in PAI1-controlled vascularization. By revealing the essential role of BM-derived cells in CNV, it opens new opportunities for the selection of genetic therapeutic strategies targeting BM cells for CNV prevention or inhibition. 


\section{Acknowledgments}

We thank I. Dasoul, P. Gavitelli, F. Olivier, F. Skivée, and G. Roland for their excellent technical assistance.

\section{References}

1. Noel A, Maillard C, Rocks N, Jost M, Chabottaux V, Sounni NE, Maquoi E, Cataldo D, Foidart JM: Membrane associated proteases and their inhibitors in tumour angiogenesis. J Clin Pathol 2004 57:577-584

2. Carmeliet $P$, Collen D: Targeted gene manipulation and transfer of the plasminogen and coagulation systems in mice. Fibrinolysis 1996, 10:195-213

3. Grant MB, Ellis EA, Caballero S, Mames RN: Plasminogen activator inhibitor-1 overexpression in nonproliferative diabetic retinopathy. Exp Eye Res 1996, 63:233-244

4. lijima H, lida T, Murayama K, Imai M, Gohdo T: Plasminogen activator inhibitor 1 in central serous chorioretinopathy. Am J Ophthalmol 1999 127:477-478

5. Schmitt M, Wilhelm OG, Reuning U, Kruger A, Harbeck N, Lengyel E, Graeff H, Gansbacher B, Kessler H, Burgle M, Sturzebecher J, Sperl $\mathrm{S}$, Magdolen V: The urokinase plasminogen activator system as a novel target for tumour therapy. Fibrinolysis Proteolysis 2000, $14: 114-132$

6. Pedersen H, Brunner N, Francis D, Osterlind K, Ronne E, Hansen HH, Dano K, Grondahlhansen J: Prognostic impact of urokinase, urokinase receptor, and type-1 plasminogen-activator inhibitor in squamous and large-cell lung-cancer tissue. Cancer Res 1994, 54: 4671-4675

7. Bajou K, Noel A, Gerard RD, Masson V, Brunner N, Holst-Hansen C, Skobe M, Fusenig NE, Carmeliet P, Collen D, Foidart JM: Absence of host plasminogen activator inhibitor 1 prevents cancer invasion and vascularization. Nat Med 1998, 4:923-928

8. Bajou K, Masson V, Gerard RD, Schmitt PM, Albert V. Praus M, Lund LR, Frandsen TL, Brunner N, Dano K, Fusenig NE, Weidle U, Carmeliet G, Loskutoff D, Collen D, Carmeliet P, Foidart JM, Noel AS: The plasminogen activator inhibitor PAl-1 controls in vivo tumor vascularization by interaction with proteases, not vitronectin: implications for antiangiogenic strategies. J Cell Biol 2001, 152:777-784

9. Gutierrez LS, Schulman A, Brito-Robinson T, Noria F, Ploplis VA Castellino FJ: Tumor development is retarded in mice lacking the gene for urokinase-type plasminogen activator or its inhibitor, plasminogen activator inhibitor-1. Cancer Res 2000, 60:5839-5847

10. Lambert V, Munaut C, Noel A, Frankenne F, Bajou K, Gerard R Carmeliet P, Defresne MP, Foidart JM, Rakic JM: Influence of plasminogen activator inhibitor type 1 on choroidal neovascularization FASEB J 2001, 15:1021-1027

11. Asahara T, Masuda H, Takahashi T, Kalka C, Pastore C, Silver M Kearne M, Magner M, Isner JM: Bone marrow origin of endothelia progenitor cells responsible for postnatal vasculogenesis in physiological and pathological neovascularization. Circ Res 1999 85:221-228

12. Lyden D, Hattori K, Dias S, Costa C, Blaikie P, Butros L, Chadburn A Heissig B, Marks W, Witte L, Wu Y, Hicklin D, Zhu ZP, Hackett NR, Crystal RG, Moore MAS, Hajjar KA, Manova K, Benezra R, Rafii S: Impaired recruitment of bone-marrow-derived endothelial and hematopoietic precursor cells blocks tumor angiogenesis and growth. Nat Med 2001, 7:1194-1201

13. Luttun A, Carmeliet G, Carmeliet P: Vascular progenitors: from biology to treatment. Trends Cardiovasc Med 2002, 12:88-96

14. Carmeliet P: Angiogenesis in health and disease. Nat Med 2003 9:653-660

15. Mueller MM, Fusenig NE: Tumor-stroma interactions directing phenotype and progression of epithelial skin tumor cells. Differentiation 2002, 70:486-497

16. Bajou K, Maillard C, Jost M, Lijnen RH, Gils A, Declerck P, Carmeliet $P$, Foidart JM, Noel A: Host-derived plasminogen activator inhibitor-1 (PAl-1) concentration is critical for in vivo tumoral angiogenesis and growth. Oncogene 2004, 23:6986-6990

17. Maillard C, Jost M, Romer MU, Brunner N, Houard X, Lejeune A Munaut C, Bajou K, Melen L, Dano K, Carmeliet P, Fusenig NE,
Foidart JM, Noel A: Host plasminogen activator inhibitor-1 promotes human skin carcinoma progression in a stage-dependent manner. Neoplasia 2005, 7:57-66

18. Csaky KG, Baffi JZ, Byrnes GA, Wolfe JD, Hilmer SC, Flippin J, Cousins SW: Recruitment of marrow-derived endothelial cells to experimental choroidal neovascularization by local expression of vascular endothelial growth factor. Exp Eye Res 2004, 78:1107-1116

19. Rakic JM, Lambert V, Devy L, Luttun A, Carmeliet P, Claes C, Nguyen L, Foidart JM, Noel A, Munaut C: Placental growth factor, a member of the VEGF family, contributes to the development of choroidal neovascularization. Invest Ophthalmol Vis Sci 2003, 44:3186-3193

20. Lambert V, Munaut C, Carmeliet P, Gerard RD, Declerck P, Gils A, Claes C, Foidart JM, Noel A, Rakic JM: Dose-dependent modulation of choroidal neovascularization by plasminogen activator inhibitor type 1: implications for clinical trials. Invest Ophthalmol Vis Sci 2003, 44:2791-2797

21. Paget S: The distribution of secondary growths in cancer of the breast. Lancet 1889, 1:571-573

22. Sengupta N, Caballero S, Mames RN, Butler JM, Scott EW, Grant MB: The role of adult bone marrow-derived stem cells in choroidal neovascularization. Invest Ophthalmol Vis Sci 2003, 44:4908-4913

23. Tomita M, Yamada H, Adachi Y, Cui Y, Yamada E, Higuchi A, Minamino $\mathrm{K}$, Suzuki $\mathrm{Y}$, Matsumura M, Ikehara S: Choroidal neovascularization is provided by bone marrow cells. Stem Cells 2004, 22:21-26

24. Ziegelhoeffer T, Fernandez B, Kostin S, Heil M, Voswinckel R, Helisch A, Schaper W: Bone marrow-derived cells do not incorporate into the adult growing vasculature. Circ Res 2004, 94:230-238

25. Coussens LM, Tinkle CL, Hanahan D, Werb Z: MMP-9 supplied by bone marrow-derived cells contributes to skin carcinogenesis. Cell 2000, 103:481-490

26. Hicklin DJ, Ellis LM: Role of the vascular endothelial growth factor pathway in tumor growth and angiogenesis. J Clin Oncol 2005, 23:1011-1027

27. de Palma M, Naldini L: Role of haematopoietic cells and endothelial progenitors in tumor angiogenesis. Biochem Biophys Acta 2006 1766:159-166

28. Göthert JR, Gustin SE, van Eekelen JAM, Schmidt U, Hall MA, Jane SM, Green AR, Gottgens B, Izon DJ, Begley CG: Genetically tagging endothelial cells in vivo: bone marrow-derived cells do not contribute to tumor endothelium. Blood 2004, 104:1769-1777

29. Rajantie L, IImonen M, Alminaite A, Ozerdem U, Alitalo K, Salven P: Adult bone marrow-derived cells recruited during angiogenesis comprise precursors for periendothelial vascular mural cells. Blood 2004 , 104:2084-2086

30. Machein MR, Renninger S, Lima-Hahn E, Plate KH: Minor contribution of bone marrow-derived endothelial progenitors to the vascularization of murine gliomas. Brain Pathol 2003, 13:582-597

31. Peters BA, Diaz LA, Polyak K, Meszler L, Romans K, Guinan EC, Antin $\mathrm{JH}$, Myerson D, Hamilton SR, Vogelstein B, Kinzler KW, Lengauer C: Contribution of bone marrow-derived endothelial cells to human tumor vasculature. Nat Med 2005, 11:261-262

32. Rafii D, Lyden D, Benezra R, Hattori K, Heissig B: Vascular and haematopoietic stem cells: novel targets for anti-angiogenesis therapy? Nat Rev Cancer 2002, 2:826-835

33. Aghi M, Chiocca EA: Contribution of bone marrow-derived cells to blood vessels in ischemic tissues and tumors. Mol Ther 2005 12:994-1005

34. Balkwill F, Coussens LM: Cancer: an inflammatory link. Nature 2004 431:405-406

35. Benelli R, Morini M, Carrozzino F, Ferrari N, Minghelli S, Santi L, Cassatella M, Noonan DM, Albini A: Neutrophils as a key cellular target for angiostatin: implications for regulation of angiogenesis and inflammation. FASEB J 2002, 15:267-269

36. Mueller MM, Fusenig NE: Friends or foes-bipolar effects of the tumour stroma in cancer. Nat Rev Cancer 2004, 4:839-849

37. Skobe M, Fusenig NE: Tumorigenic conversion of immortal human keratinocytes through stromal cell activation. Proc Natl Acad Sci USA 1998, 95:1050-1055

38. Masson V, de la Ballina LR, Munaut C, Wielockx B, Jost M, Maillard C, Blacher S, Bajou K, Itoh T, Itohara S, Werb Z, Libert C, Foidart JM, Noel A: Contribution of host MMP-2 and MMP-9 to promote tumor vascularization and invasion of malignant keratinocytes. FASEB $\mathrm{J}$ 2005, 19:234-236

39. Czekay RP, Aertgeerts K, Curriden SA, Loskutoff DJ: Plasminogen 
activator inhibitor-1 detaches cells from extracellular matrices by inactivating integrins. J Cell Biol 2003, 160:781-791

40. Deng G, Curriden SA, Wang S, Rosenberg S, Loskutoff DJ: Is plasminogen activator inhibitor- 1 the molecular switch that governs urokinase receptor-mediated cell adhesion and release? J Cell Biol 1996, 134:1563-1571

41. Devy L, Blacher S, Grignet-Debrus C, Bajou K, Masson R, Gerard RD, Gils A, Carmeliet G, Carmeliet P, Declerck PJ, Noel A, Foidart JM: The pro- or antiangiogenic effect of plasminogen activator inhibitor 1 is dose dependent. FASEB J 2002, 16:147-154
42. Urbich C, Heeschen C, Aicher A, Sasaki K, Bruhl T, Farhadi MR, Vajkoczy P, Hofmann WK, Peters C, Pennacchio LA, Abolmaali ND, Chavakis E, Reinheckel T, Zeiher AM, Dimmeler S: Cathepsin L is required for endothelial progenitor cell-induced neovascularization. Nat Med 2005, 11:206-213

43. Basire A, Sabatier F, Ravet S, Lamy E, Mialhe A, Zabouo G, Paul P, Gurewich V, Sampol J, Dignat-George F: High urokinase expression contributes to the angiogenic properties of endothelial cells derived from circulating progenitors. Thromb Haemost 2006, 95:678-688 